\title{
Reducing the Negative Effects of Seasonal Demand Fluctuations: A Proposal Based On Cost-Benefit Analysis
}

\author{
Tarkan Tunç*, Arzum Büyükkeklik** \\ *Graduate School of Social Sciences, Ömer Halisdemir Üniversity, Turkey \\ **Department of International Trade and Logistics Management, Ömer Halisdemir Üniversity, Turkey
}

\begin{abstract}
Demand fluctuations and irregular production evolved as a result of these fluctuations are an important problem for manufacturers. In this study, problems such as high production costs caused by seasonal demand fluctuations and inability of delivering orders on time to the customer are analyzed in the case of a manufacturing firm. The proposal of utilizing production full capacity every month and storing produced goods without brand labels printed on to reduce the production costs was discussed.
\end{abstract}

Keywords: Demand Uncertainty, Seasonal Demand Fluctuations, Supply Chain Management, Warehouses.

\section{INTRODUCTION}

Demand uncertainties and fluctuations in today's intense competition environment is one of the important problems faced by manufacturing enterprises [1]. When the amount of demand failed to be predicted correctly, it is not possible to make planning correctly for the production capacity, purchasing procurement process, logistics activities. The effect of processes failed to be scheduled exhibits itself also in the payment balance leading to adverse structural influences. In addition to these negative in-business effects, also the customer dissatisfaction caused by the prices by which also the orders not completed within the lead times from outsources or the costs increased are reflected develops as well. Therefore, since reducing the demand uncertainties would show a direct positive effect on business performance [2]. firstly using the powerful demand estimation methods, it is aimed to reduce or completely eliminate the uncertainties. However, demand is closely related to non-business environmental factors in most cases, achievement here of does not always become possible completely. In cases where the ambiguousness's failed to be fully eliminated, it is required to develop the approaches which would reduce the adverse effects of such fluctuations.

On the other hand, the effects of demand uncertainties and fluctuations do not only remain at the level of manufacturing enterprise, but also the entire supply chain which might lead to inefficient processes and non-value-creating activities throughout the supply chain [3], [4]. The warehouses and storage function are also inseparable parts of the supply chain as much as that of production activities in reducing the adverse effects of demand uncertainties in this context [5] and has a critical importance on the success of such activities [6].

In this study, a proposal oriented towards developing resolution of problems caused by the seasonal influences - induced fluctuations experienced at a company operating in the chemistry sector has been debated. The aim of the study is the demand uncertainty and fluctuations caused problems resulting in failure to deliver the orders to the customer in time and emerging to be customer dissatisfaction and constituting high costs within the context of a firm to be scrutinized and a low-cost resolution proposal -oriented towards identified problems to be developed.

The rest of the paper is organized as follows: In the next section the theoretical framework, related to the warehouse management and uncertainty and fluctuations in demand have been talked about. In section three, the existing production structure of company has been scrutinized and the proposal related to the fundamental parameters developed have been explained. As for the fourth and last section, possible outcomes of the solution proposal have been evaluated and suggestions for both the development of the current study and future research oriented proposals have been presented.

\section{II.THEORETICAL FRAMEWORK}

\subsection{Warehouses}

The warehouses are the commercial purpose spaces that are used for the storage activities and distribution of raw materials, semifinished products and finished products and the basic function of which is to keep commodities in stock. The stocks are the high value physical assets which are directly or indirectly involved in manufacturing the finished products. This value is the quantities of the assets or their material provisions. Despite having a cost generation potential, the stocks also have a potential that ensures upgrading the customer service level [7]. The most important reason for having stock is the failure of supply in meeting the demand. Through prevention of stagnations during these processes, 
the stocks offer solution to such deficiencies by ensuring persistence in the activities, reducing the effects experienced on the supply side due to the length of the production/distribution processes, making the activities independent, reducing interfunctions dependencies, decreasing the effects of uncertainties seen to be the forecast deviations particularly on the demand planning side and allowing the producer to make use of the scale economy by making more convincement - cost purchases [8], [9].

While the warehouses can be found inside or nearby the production facilities, they can also be built in form of separate and specific structures [10]. Depots serve as a kind of bridge providing a link between production and consumption [11]. The yare used for the periodical requirements (like sugar beet), seasonal requirements (like umbrella), large - scale productions (bulk export by ship), continuous production, fast procurement and balancing the product prices.

Storage has a very important role for the modern supply chains [12], [10]. Warehouses make a significant contribution to the supply chains to operate in line with the specified goals and execution of logistics activities in an active way. They also provide tremendous advantages to the enterprises to get prepared for the economic trends and seasonal changes. These advantages emanate from its direct impact on the variances of promoting the warehouse's customer service level, reducing the logistical costs and augmenting work performances [12].

The warehouses have significant benefits such as increasing logistical performance, minimizing the effects of production induced breakdowns and downtimes and enrichment of facilities of offering additional customer services to the customer like labeling, promotion / encouragement and assembling / packaging operations and lowering transport costs by decreasing number of shipments, ensuring the quantity balancing by securing continuity of production prior to the season or in periods when the number of orders placed was lower and allowing customers utilize quantity discounts in processes of purchasing [11], [13]. They make contribution to the supply chain to operate in line with the targeted objectives and to the logistical activities to be effectively carried out. The cases where the storage operations were articulated in form of activities adding value to the supply chain to the end of retail chains are encountered in the literature.

As for being contrary to these benefits, whereas the warehouses and storage activity represent the stability, they may lead to very serious problems for both producers and the entire supply chain whenever unsuccessful inventory managements take place. These problems like high inventory costs, safety risks, product shelf life span and clumsiness may be reckoned among these problems. It is a reality that the traditional storage methods exert a considerable pressure on the functions of operation. Therefore, in terms of companies, when the warehouses and storage activities are managed well, they can deliver competition advantage, they become the critical matters pointing out rising costs and inefficiency in the case of poor management. For this reason, issues related to storages and storage activities draw attention from both academicians and practitioners [14].

\subsection{Demand Uncertainties and Seasonal Demand Fluctuations}

Demand fluctuation is an important uncertainty state contained in the foundation of production, employment and capacity utilization of companies in short term and under full competition conditions [15]. Manufacturing enterprises generally adopt traditional methods, such as stock based and capacity increased operation when faced with uncertainties in demand and fluctuations in sales. This situation might be applied whenever the producer companies are encountered with the fluctuations in supply and demand, they tend to keep stocks at safe levels or increase the production capacities.

In relation to the issue, [16] have investigated whether or not there is any connection between the stock volatility and uncertainty in sales and determined that the uncertainty had a positive effect on inventory building behavior. Similarly, also [17] has identified that the demand uncertainty was a very significant and positive effect on the investments. According to the result of his study he has accomplished using the annual data of medium and large scale enterprises, in order not to get caught without stock, the companies keep an inventory and when the effect of demand uncertainty is taken into consideration, the financial strength role of company over inventory indicates similar behaviors in almost all countries.

On the other hand, while the manufacturers who did not financially experiences any difficulty tended to evaluate other more effective methods such as using abroad resource or labor leasing instead of [16], increasing their stock levels to overcome the demand shocks. In the case where the producer enterprises have preferred to increase capacity in fighting against demand uncertainties, working overtime, outsourcing and maintaining contracted labor force possibilities are used extensively. The contracted labor force is evaluated to reduce labor costs, increase labor productivity and balance production according to demand volatility. Since the use of contracted labor force is required to be able to overcome the supply and demand fluctuations and considered as the 
simple way of preventing the capacity squandering by stocking them, thus the costs of holding them in hand is considered to be able to be kept balanced with the capacity costs [18].

Similarly, new and modern approaches such as utilization of external resources, development of flexible production strategies, demand uncertainties or fluctuations from external sources, developing flexible production strategies, investing to manufacturing technologies, efficient warehouse management and intensifying communication in the supply chain are also developed against demand uncertainties or fluctuations. There are studies in the literature in which these approaches were taken as topics by various researchers. Outsourcing is an implementation where a company ensures the cost advantage by focusing on its core competences and purchasing other activities from the specialized firms. [19] have found that there was an asymmetrical relationship between sales and outsourcing. According to this, while less resource usage realized the market - happened high demand conditions versus low future estimates, on the contrary, namely, use of more foreign resource realizes under lower demand conditions. The reason hereof is due to indispensability with the use of foreign resource versus high estimate-low sales developments. This reveals how much significant the processes of demand estimation and procurement and planning are for an operation.

As another method, the producers evaluate the flexible production strategies to be able to overcome unpredictable changes in demand happened [20]. [21] has examined the flexible technology and flexible capacity approaches oriented towards fulfillment of demand fluctuations. In the study, it has been emphasized that the flexible technology investments have improved the total production costs, as for the flexible capacity investments, they have provided the possibility of postponement of production decisions until actual demand quantities became available. In this context, while the flexible technology became effective on the production costs, it is effective on the flexible production quantities. As to the actual production flexibility, it is achievable through the evaluation of both together. On the other hand, higher flexibility does not mean more profitability, while flexible technology usually leads to higher profitability; it is known that its damage may also be seen as well as benefit of flexible capacity. Again being related to the flexibility, [22] have looked through the technological investments and flexible capacity strategies the companies have set about to be able to overcome the increased environmental variances like the demand uncertainties. A three stage decision model comprising the technological level, capacity volume and production quantity parameters have been presented for the influence of cost structure for the technologic investments on the strategic and operational decisions of company to be revealed. It has been defended that appropriate technological investments (like adapting advanced level technologies) will improve the overall cost structure by increasing the operational efficiency. However, the flexible production strategies can not only be developed by investments but also with various arrangements in the existing production system. For example in the study carried out by [23] in the clothing industry, they have created a line adjustment model related to planting processes harboring many operations herein. With this flexibility upgraded joining lines, the loss costs happening due to operational costs, processing costs, capacity increase costs, and foreign resource utilization costs have been minimized.

While the demand uncertainties or fluctuations affect the production function, it also affects whole supply chain very seriously. Therefore, the ability to respond to the unexpected events as quickly and accurately as possible within the supply chain as a whole bears a vital significance. Supply chains are already of indecisiveness and fluctuation recipient. Being oriented towards reducing the uncertainties, as for the benefits of sharing demand forecasts along the supply chain, they are quite high [24]. [25] have proposed a quantitative approach which assesses the integration of inventory and safe stock levels to establish a sensitive chain that can give a rapid response to the demand changes under demand uncertainty from the studies previously accomplished on this subject. The sensitivity in this study has been stated to be transportation time, waiting time, cycle planning of multi product cycle planning and inventory management. Similarly [26] has studied on the product, process and volume which he considered as the three basic factors determining supply chain sensitivity.

\section{PROBLEM ANALYSIS AND SOLUTION PROPOSAL}

In this section, primarily the problems experienced in the company due to seasonal demand fluctuations have been identified and a proposal for the establishment of new warehouses being oriented towards settlement of such problems has been developed. Carrying out a cost-benefit analysis has been put forward by assessing the proposed structure in terms of benefits and the costs to happen.

\subsection{Definition of Problem}

The company where this study was accomplished is a company which is in the large scale status operating in the chemical sector with its 850 employees working at its 5 production 
facilities across Turkey. It is also listed on the list of 500 large industrial enterprises (ISO 500) declared by Istanbul Chamber of Industry publishes every year.

Most of the products produced by the company are used within Turkey. All distributions are being shipped from 5 production plants across the country. The company meets its logistical activities largely by its own facilities and receives support from the logistics companies in special cases.

The activities firm's distribution network commences when the orders received from customers are entered by distributors or sales representatives into the sales system using common software. Each order entered falls into the relevant production plant momentarily. Firm's distribution channel is designed as easy to use and access for customers.
The production plants are found in 5 different cities domestically (in pursuant to confidentiality, these cities are assumed to be Izmir, Adana, Ankara, Erzurum and Kocaeli situated in different locations in Turkey) and the orders are accepted within the scope of the responsibilities divided on the basis of provinces. When looked at the annual sales curves of the facilities, it is seen that starting from spring months; the orders have intensified and have decreased at the expiry of autumn months. And also the regional market distributions are based on the principle that every plant primarily satisfies the orders entered from its own responsibility area. Fig. 1 showing the monthly average orders of the plants in recent 3 years between 2014-2016 is given below.

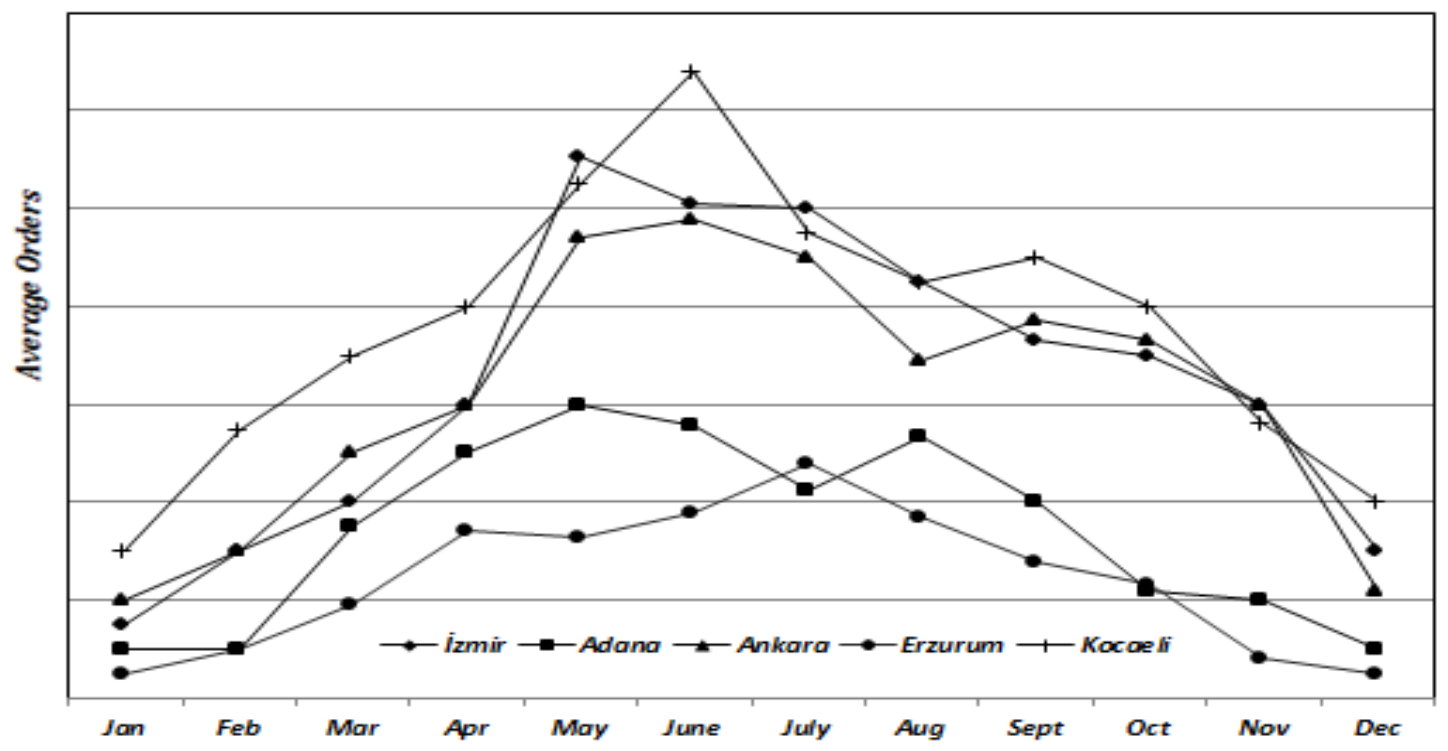

Fig. 1. Monthly average orders of the plants

It is understood that the orders which started increasing as from the month of March in comparison to monthly order averages contained at Fig. 1. This seasonal fluctuation in the orders, naturally in the product demands leads to a significant planning problem and a rise in the costs for the company.

In order to meet the demands on time, starting from the months when order density began increasing, the facilities gradually increase their production quantities by exercising the overtime and /or additional shifts. Additional shift implementation is carried out with the contracted (temporary) staff. However, such implementation also brings along various difficulties such as difficulty in finding temporary employees (particularly for the plants of low population provinces), the qualification levels of recruited temporary staff being below the level expected, the problems of adaptation to the enterprise and working environment, the risks undertaken within the work safety and the strictness of laws and regulations and restrictions. Overtime application increases the costs. Therefore, increasing the production quantity with overtime and / or additional shifts in production during the periods of increased order intensity is not regarded by the top management of operations as a sustainable method. On the other hand, as the choice of technology investments and renewing the production system and increasing the production capacity would also create a surplus capacity in the months staying outside certain periods at the plants, it is not being considered as a solution. Even in current capacity, the production quantities can fall down to $59 \%$ of the capacity in the winter months during low order periods, which creates a surplus capacity (for example: Erzurum Plant at Table 1). In addition, the company produces the same product under different brand names. 
Therefore, currently as the production is made according to the order, in occurrence of an order cancellation, the products with trademark was affixed thereon are likely to remain in the inventory for a long time.

\subsection{Development of the Proposal}

When the conditions in which company operates were evaluated, the proposal for the products produced without any trademark labels during the periods of seasonal low demand and full capacity production failed to be used to evaluate such surplus capacity to be stocked at the new warehouses has been presented. According to this, the products stocked being unlabeled would be labeled according to the relevant brand in line with incoming orders, thus flexible and rapid fulfillment of demand would be possible. The labeling work performed at the final stage of production would be shifted to the new warehouse spaces. Upon use of new warehouses, the trademark based sell out state would also decrease and customer satisfaction would increase. Bearing the order cancellation induced cost (stock) of retention would not be required either.

Essential parameters of developed proposal have been put forth below and its feasibility has been discussed. The proposal has been evaluated with the comparative calculation of surplus capacity and annual total order quantities and comparing it with the number of employees in process of production.

At the Table 1 below, 2015 monthly average demand quantities and current capacities for the five plants belonging to the company have been provided. For example, when the monthly average demand to be 6.460 ton / month and the capacity to be 7.120 ton / month are evaluated, a 660 ton capacity remains surplus for Izmir plant. According to this, the monthly average surplus capacity exceeds $9 \%$. As for other plants, ratio of monthly average surplus capacity is higher, goes up to $40 \mathrm{~s} \%$. Furthermore, since these figures are for the 12 month average, they are lower. In fact, the ratio of monthly average surplus capacity is likely to rise up to $70 \mathrm{~s} \%$ according to the information taken from the managers of companies.

$\underline{\text { Table 1. Monthly average demand, current production capacities and surplus capacities of plants }}$

\begin{tabular}{lccccc}
\hline & $\begin{array}{c}\square \text { mir } \\
\text { Plant }\end{array}$ & $\begin{array}{c}\text { Adana } \\
\text { Plant }\end{array}$ & $\begin{array}{c}\text { Ankara } \\
\text { Plant }\end{array}$ & $\begin{array}{c}\text { Erzurum } \\
\text { Plant }\end{array}$ & $\begin{array}{c}\text { Kocaeli } \\
\text { Plant }\end{array}$ \\
\hline Monthly demand (ton/month) & 6.460 & 3.410 & 6.170 & 2.400 & 7.610 \\
Monthly production capacity (ton/month) & 7.120 & 3.850 & 7.940 & 4.050 & 9.760 \\
Monthly surplus capacity (ton/month) & 660 & 440 & 1.770 & 1.650 & 2.150 \\
Monthly surplus capacity ratio & 0,09 & 0,11 & 0,22 & 0,41 & 0,22 \\
\hline
\end{tabular}

On the other hand, when the demands are analyzed by being detailed monthly, a different situation occurs and while surplus capacity happens during some months, existing capacity remains inadequate during some months. Capacity requirement and surplus capacity distribution are shown in Fig. 2 as an example for Izmir plant. According to this, current capacity of plant is at the capable level of meeting the orders in JanuaryApril and October-December period. However, a demand above capacity happens in MaySeptember period and fulfillment of orders could not be possible. In this period, the company is obliged to implement overtime and / or additional shifts. This situation applies to other production facilities as well.

\section{İzmir Plant's Demand Quantities and Capacity Distribution}

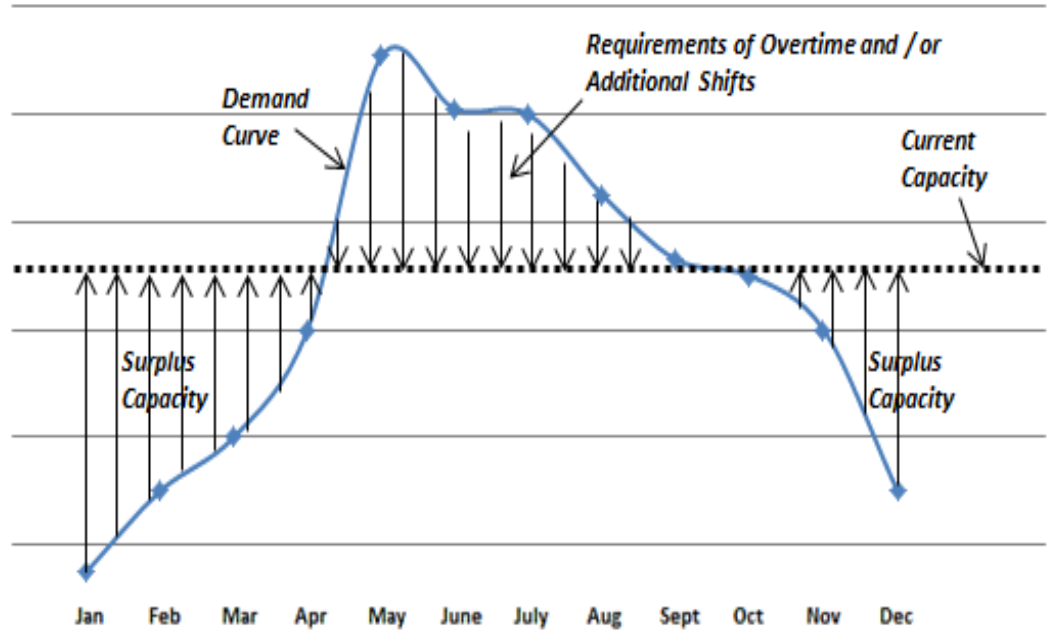

Fig. 2. İzmir Plant's demand quantities and capacity distribution for 2015 
It is understood that in fact, all of the demands could be met single (one) shift system, by expanding the capacity (using the full capacity in all months of year) so as to cover entire year without leaving any surplus capacity or even as much difference amount of excess demand production as seen at Table 1 could be realized at every plant. However, this situation would bring along the problem of storing the products and it would be necessary to keep the products manufactured during low demand months without being labeled with brand name until the demand for products promotes.
In Table 2, annual total demand quantities of the plants were calculated and accordingly the required storage area for the plant in each different location was determined. As a result of the evaluations made by the company managers, the pre-acceptance of inventory spaces required to be in size to accommodate at least $20 \%$ of annual product demand of the plants has been made. This acknowledgment has been used in calculation of minimum warehouse sizes that would receive products which might be produced in excess demand.

Table 2. Calculation of storage area requirements

\begin{tabular}{lccccc}
\hline & $\begin{array}{c}\text { zmir } \\
\text { Plant }\end{array}$ & $\begin{array}{c}\text { Adana } \\
\text { Plant }\end{array}$ & $\begin{array}{c}\text { Ankara } \\
\text { Plant }\end{array}$ & $\begin{array}{c}\text { Erzurum } \\
\text { Plant }\end{array}$ & $\begin{array}{c}\text { Kocaeli } \\
\text { Plant }\end{array}$ \\
\hline Annual total demand (ton) & 77.500 & 40.900 & 74.000 & 28.800 & 91.300 \\
Storage area capacity (ton) & 15.500 & 8.180 & 14.800 & 5.760 & 18.260 \\
Storage area requirements ${ }^{*}\left(\mathbf{m}^{\mathbf{2}}\right)$ & 9.920 & 5.235 & 9.472 & 3.687 & 11.686 \\
\hline Note: As vertical and multi - storey stocking is made due to structure of product, the space requirement as \\
per ton of product is $0.64 \mathrm{~m}^{2}$. The indoor space requirement is calculated accordingly.
\end{tabular}

Total number of personnel required for the current situation and the proposed warehouse is provided at Table 3 by taking again Izmir plant as a model. The superiority of warehouse proposal would be revealed in comparison to existing situation in terms of costs and number of personnel as well. To do so, three different cost studies have been actualized within the scope of personnel budgets. The first one of these is the calculation made over the number of permanent staff in the period when the demand was low. The number of personnel required to be available in department permanent personnel have been calculated by the studies carried out within the scope of norm staff considering different scenarios and the staff recruitments have been calculated accordingly. The basic approach is based on the assumption that all machines, equipments and lines are in operable condition within single shift system. The second calculation is related to the costs accured by the permanent staff recruited during the period expressed to be demand intensive season. And the third cost item comprises the extra costs emerged in form of overtime during high period.

Table 3. The number of personnel

\begin{tabular}{cccc}
\hline \multicolumn{2}{c}{$\begin{array}{c}\text { Current situation } \\
\text { (The number of personnel) }\end{array}$} & \multicolumn{2}{c}{$\begin{array}{c}\text { Proposed situation } \\
\text { (The number of personnel) }\end{array}$} \\
\hline low-demand period & high-demand period & low-demand period & high-demand period \\
39 & 52 & 39 & 39 \\
\hline
\end{tabular}

According to the information obtained from the company, the extra annual wages paid in the single shift system have realized to be approximately TL 68.000 with a calculation made over the numbers of existing norm permanent staff to $(52-39=13$ persons $)$ described to be over labor force and to staff members who did not get involved in the production activities even though they were within the norm permanent staff during low demand period. And the extra charges paid on the basis of annual external variables to the personnel above the contracted personnel expressed to be labor force for establishment of additional one more shift during high demand period have realized approximately as TL 249.600.

13 (persons) *3.200 TL (gross salary) *6 $($ month $)=249.600 \mathrm{TL}$

The wages paid annually for overtime during the demand intensive period, depending on many internal and external variables have actualized to be approximately TL 41.000 (according to the information obtained from the company). So, annual total costs are approximately TL 358.600 $(68.000+249.600+41.000)$ in current situation.

In case where proposal for establishment of new warehouses is implemented, the monthly production capacities of plants will have turned into fully usable state and there shall be no need for overtime and / or additional shifts and increasing the number of personnel during demand rising period. However, the costs of employment for the new employees as per new warehouse and rental costs of warehouse spaces will happen. To eliminate both this necessity and to prevent occurrence of the second handling costs of the products, establishment of proposed warehouses is decided to be installed at the nearest point to the production plants within the settlement of facilities. 
In this respect, the warehouse rental costs or construction costs and transportation costs will not be occurred; additional personnel expenses will not accrue due to utilization of the personnel to work at the newly constructed warehouses from the existing norm permanent staff.

On the other hand, proposed situation will increase inventory costs. It is again examined in the case of the İzmir plant. There is a 15.500 ton inventory at Izmir plant annually. According to the information obtained from the company managers, it has been calculated that approximately a 2,1 month inventory would happen if production were made in full capacity. Since the monthly inventory turnover rate is 2,1 months, the monthly inventory cost would be TL 75.000 and this is calculated as $2,1 \times 75.000=\mathrm{TL} 157.500$. In this context, it is envisaged that the proposal shall provide a significant cost advantage when the costs with the proposed solution and the costs in current situation are compared.

Due to establishment of new warehouses, the production which would be maintained in regular quantities will enable also the suppliers to make regular production within this period. The seasonal fluctuation induced drop in production quantities affects both the suppliers negatively and they have been obliged to tolerate similar additional costs within this period as well. With the proposed solution, a drop in the costs of suppliers might be expected. Moreover, it is also expected that the proposed solution would make contribution also to the logistics companies that have difficulties in finding cargo due to reduced production quantities. Therefore, the earnings would multidimensionally promote; the manufacturer company would reduce labor costs and procure its requirements like raw materials and packaging materials at more affordable prices and improve its logistics costs.

\section{RESULTS AND RECOMMENDATIONS}

Demand fluctuations and irregular production quantities dependent hereto are the processes when the production facilities are forced to keep going. Nevertheless, producers are supposed to act in such a way to acquire faster and more effective results reconstructing their product and raw material stock capacities in parallel with the change in demand in comparison to former ones. The ability to respond rapidly to the fluctuations in demand is also an indicator for the successful competitiveness of companies. In order to achieve this, they need to shorten their response times and develop new applications which would reduce all costs, especially logistics costs when shortening it.

However, meeting the demand fluctuating is not only the matter of cost, but also the source of planning, productivity and motivation in terms of both managers and employees. In order to meet this rise in demand, the manufacturing companies may go for outsource usage or contracted labor force such as overtime, additional shifts, machine and labor leasing, thereby they try lowering also their operational costs while raising their demand fulfillment levels. However, they are encountered with the losses in process of getting adapted to working environment by the contracted personnel hired to meet the increased demands and invisible costs such as overtime and shift implementation dependent performance drops and losses of motivation, faulty production or wrong loading made, serious business safety risks and training costs happened, outsourcing use - caused poor quality and quantity problems as well. In this study, being developed by a production company for elimination of negativities like increased costs and irregular production capacity utilization lived as a result of seasonal demand fluctuations; the proposal to use the full production capacity as per month and storage of product stocks to happen has been discussed.

The proposed recommendation can be summarized as the storage of products produced above ordered quantity by maintaining one-shift system running throughout the year and stocks to be used to meet increased demands. The proposal has been developed in consideration of data for five affiliated production plants of company established in different cities of Turkey. With the proposal, both the production capacity rates of the company owned plants will increase and also month based more stable capacity utilization rates shall be likely realize within the year. By virtue of this, the production planning activities will become easier. Moreover, the need for seasonally increased orders induced application of additional shifts and / or overtime work would disappear and it would be possible to prevent experiencing above mentioned discomforts. The stable amounts to be acquired upon application of proposal would make contribution for more appropriate costs of raw material costs to shape up due to smaller stock area, seasonally equal raw material requirement and seasonal abroad purchases; therefore it would ensure gains in terms of purchasing activities too.

In the literature, one of the justifications for the negative perspective of enterprises related to their warehouses run with stock is the fact that cost rise in stocks which would start with the producer would be reflected to the entire supply chain and finally to the customer. However, the demand as a result of comparison of current system versus proposed system might be enumerated to be the drop in labor costs, facilitated production planning process, expected reductions in raw material purchasing costs, expected improvement in labor performance due to stable working arrangement 
and rapid satisfaction of customer demands despite demand fluctuations.

Of course, in addition to these gains, the risks of storing finished products would also be in question. These risks and how they could be eliminated have explained below:

- The product is a a dry chemical material so it does not deteriorate.

- The product does not have special difficulties in storage.

- Since the demand estimations pertaining to the product are determined as a result of sound market surveys, it is being assumed that non sale probability of products is low.

In this study, due to restrictions in sharing the company information, only demand quantities,

\section{REFERENCES}

[1]. Abid, M. and Özkan, S., The Relationship Between Lean Manufacturing \& Customer's Demand Uncertainty, Tekniska Högskolan, Thesis Work, 2009.

[2]. Begen, M.A., Pun, H. and Yan, X., Supply and Demand Uncertainty Reduction Efforts and Cost Comparison, Int. J. Production Economics 180, 2016, 125-134.

[3]. Pac, M.F., Alp, O. and Tan, T., Integrated Workforce Capacity and Inventory Management Under Temporary Labor Supply Uncertainty, International Journal of Production Research 47 (15), 2009, 42814304.

[4]. Patil, P.D., Shrotri, A.P. and Dandekar, A.R., Management of Uncertainty in Supply Chain, Int., Journal of Emerging Technology and Advanced Engineering 2 (5), 2012, 2250-2459.

[5]. Gu, J., Marc Goetschalckx, M., and McGinnis, L.F., Research on Warehouse Operation: A Comprehensive Review, European Journal of Operational Research 177, 2007, 1-21.

[6]. Bakker, M., Riezebos, J., and Teunter, R.H., Review of Inventory Systems with Deterioration Since 2001, European Journal of Operational Research 221, 2012, 275284.

[7]. Ertuğrul, İ. and Tanrıverdi, Y., ABC Method for Stock Controls and the Application of the AHP Analysis to Yarn Company, International Journal of Alanya Faculty of Business 5 (1), 2013, 41-52 (in Turkish).

[8]. Tersine, R.J., Principles of Inventory and Materials Management (2nd Ed, 1994).

[9]. Jacobs, F.R., Chase, R.B. and Lummus, R.R., Operations and Supply Chain Management (Mcgraw-Hill Irwin, 3th Edition, 2013).

[10]. Rajuldevi, M.K., Veeramachaneni, R. and Kare, S., Warehousing in Theory and number of labor force and costs plus cost information on holding them in the inventory were used. A detailed cost - benefit analysis where the costs caused by the current production system not being demand fluctuations sensitive (such as the amount of uncompleted annual order quantity and additional costs brought along) and the benefits expected to be created from the utilization of proposed full production based production structure (such as advantages in raw material purchasing costs) were compared could not be introduced. The proposals to be brought along for the demand fluctuations and ambiguities in future studies can be scrutinized with more detailed case studies.

Practice, A case study at $\ddot{O} o B$, University of Boras, 2008.

[11]. Hompel, M. and Schmidt, T., Warehouse Management, Automation and Organisation of Warehouse and Order Picking Systems (Springer, 2007).

[12]. Suvittawatt, A., Majors Factors For Effective Warehouse Management: Eastern Part of Thailand Perspective, IJABER 14 (6), 2016, 3757-3763.

[13]. Karakış, İ, Başkak, M. and Tanyaş, M., Conventional/Automatic Warehouse Decision Problem: An Analytical Model, XI. International Logictics\&Supply Chain Congress, 2013, Kayseri.

[14]. Kadric, E., Bajric, H. and Pasic, M., Demand Modeling with Overlapping Time Periods, Procedia Engineering 100, 2014, 305-313.

[15]. Zimmermann, K.F., Flexibility in the face of demand fluctuations: Employment, capacity utilization, and industry structure, International Journal of Industrial Organization 13, 1995, 179-193.

[16]. Çağlayan, M., Maioli, S. and Mateut, S., Inventories and Sales Uncertainty, Journal of Banking \& Finance 36 (9), 2012, 25122521.

[17]. Bo, H., Volatility of Sales, Expectation Errors, and Inventory Investment: Firm Level Evidence, International Journal of Production Economics 72 (3), 2001, 273283.

[18]. Dellaert, N.P., Flapper, S.D.P., Jeunet, J., and Tan, T., Integrated Capacity and Inventory Decisions, Operations Research Proceedings, 2011, 463-468.

[19]. Bakhtiari, S. and Breunig, R., New Outsourcing, Demand Uncertainty and Labor, 2015, Usage Available at: https://ssrn.com/abstract=2491489 or http://d x.doi.org/10.2139/ssrn.2491489.

https://crawford.anu.edu.au/files/uploads/crawford0 1_cap_anu_edu_au/2014-09/demout.pdf 
[20]. Hagspiel, V., Huisman, K.J.M. and Kort, P.M., Production Flexibility and Capacity Investment Under Demand Uncertainty, Finance Seminar Series, Aarhus University, April 9, 2013, 1-25.

[21]. Yang, L., Ng, C.T. and Cheng, T.C.E., Optimal Production Strategy Under Demand Fluctuations: Technology Versus Capacity, European Journal of Operational Research 214, 2011, 393-402.

[22]. Yang, L., Wang, Y., Ma, J., Ng, C.T. and Cheng, T.C.E., Technology Investment Under Flexible Capacity Strategy with Demand Uncertainty, Int. J. Production Economics 154, 2014, 190-197.

[23]. Samadhi, T. and Sumihartati, A., Model for Assembly Line Re-Balancing Considering Additional Capacity and Outsourcing to
Face Demand Fluctuations, IOP Conf. Series: Materials Science and Engineering 114, 2016, 1-10.

[24]. Barlas, Y., and Gündüz, B., Demand Forecasting and Sharing Strategies to Reduce Fluctuations and The Bullwhip Effect in Supply Chains, Journal of the Operational Research Society 62, 2011, 458473.

[25]. You, F. and Grossman, I.E., Design of Responsive Process Supply Chains Under Demand Uncertainty, Computers \& Chemical Engineering 32 (12), 2008, 30903111.

[26]. Holweg, M., The Three Dimensions of Responsiveness, Int. J. of Operations and Production Management 25, 2005, 603-622. 